\title{
Uji Aktivitas Analgetik Ekstrak Etanol Daun Inggu (Ruta angustifolia [1.] Pers) Pada Tikus Putih Jantan
}

Yane Dila Keswara1*, Sri Rejeki Handayani ${ }^{2}$

1,2Fakultas Farmasi, Universitas Setia Budi Surakarta, Jl. Letjen. Sutoyo, Surakarta

*Penulis Korespondensi. Email: yanedila.keswara@gmail.com

\section{ABSTRAK}

Nyeri merupakan perasaan tidak nyaman yang disebabkan oleh rangsangan yang kuat atau merusak, jika dibiarkan dapat mempengaruhi rutinitas sehari-hari. Penelitian ini bertujuan untuk mengetahui efek analgesik dan dosis dari ekstrak etanol daun inggu, serta untuk mengetahui keefektifan ekstrak etanol daun inggu sebagai analgesik narkotik dengan metode Tail Flick atau sebagai analgesik non narkotik dengan metode Paw Pressure Test Randall Selitto. Ekstraksi dengan cara maserasi serbuk daun inggu dengan pelarut etanol $96 \%$. Sebanyak 25 ekor tikus putih jantan galur wistar dibagi menjadi 5 kelompok, yaitu kelompok positif asam mefenamat $9 \mathrm{mg} / 200 \mathrm{~g}$ BB untuk metode Paw Pressure Test Randall selitto dan tramadol 0,9 mg/ $200 \mathrm{~g}$ BB untuk metode Tail Flick, kontrol negatif CMC Na 0,5\%, ekstrak etanol daun inggu dosis $10 \mathrm{mg} / 200 \mathrm{~g} \mathrm{BB}, 20 \mathrm{mg} / 200 \mathrm{~g}$ BB dan $40 \mathrm{mg} / 200 \mathrm{~g}$ BB. Data yang diperoleh dianalisa dengan uji ANOVA, selanjutnya digunakan uji LSD untuk mengetahui perbedaan antar kelompok. Hasil menunjukkan ekstrak dosis $10 \mathrm{mg} / 200 \mathrm{~g}$ BB, $20 \mathrm{mg} / 200 \mathrm{~g}$ BB, $40 \mathrm{mg} / 200 \mathrm{~g}$ BB memiliki efek analgetik. Dosis ekstrak $20 \mathrm{mg} / 200 \mathrm{~g}$ BB dan $40 \mathrm{mg} / 200 \mathrm{~g}$ BB pada metode Paw Pressure Test Randall selitto setara dengan asam mefenamat, dosis ekstrak 10 mg/200 g BB, 20 mg/200 g BB, dan 40 mg/200 g BB pada metode Tail Flick setara dengan Tramadol. Ekstrak etanol daun inggu lebih efektif sebagai analgesik narkotik dengan metode Tail Flick.

\section{Kata Kunci:}

Daun Inggu; Analgetik; Randall Selitto; Tail Flick

Diterima: Disetujui:

4-07-2019 7-08-2019

Online:

12-09-2019 
ABSTRACT

Pain is an uncomfortable feeling caused by strong or destructive stimulation, if unchecked can affect daily routine. This study aims to determine the analgesic effect and dosage of the leaf extract ethanol, as well as to determine the effectiveness of the leaf extract ethanol as a narcotic analgesic by the Tail Flick method or as a non-narcotic analgesic by the Paw Pressure Test Randall Selitto method. Extraction was done by maceration of leaf powder with a solvent $96 \%$ ethanol. 25 male Wistar white rats were divided into 5 groups, positive group mefenamic acid $9 \mathrm{mg} / 200 \mathrm{~g}$ BW for the Paw Pressure Test Randall Selitto Method and tramadol $0.9 \mathrm{mg} / 200$ g BW for the Tail Flick Method, negative control CMC Na 0,5\%, ethanol extract leaves inggu leaves a dose of $10 \mathrm{mg} / 200 \mathrm{~g} \mathrm{BW,} 20 \mathrm{mg} / 200 \mathrm{~g} \mathrm{BW}$ and $40 \mathrm{mg} / 200 \mathrm{~g} \mathrm{BW}$. The data obtained were analyzed by ANOVA test, then LSD test was used to determine differences between groups. The results showed extract dosage of $10 \mathrm{mg} / 200 \mathrm{~g} \mathrm{BW}, 20 \mathrm{mg} / 200 \mathrm{~g} \mathrm{BW}, 40 \mathrm{mg} / 200$ $\mathrm{g}$ BW had analgesic effect. Extract dosage of $20 \mathrm{mg} / 200 \mathrm{~g}$ BW and $40 \mathrm{mg} / 200 \mathrm{~g}$ BW in the Randall selitto Paw Pressure Test method is equivalent to mefenamic acid, extract dose $10 \mathrm{mg}$ /200 g BW, $20 \mathrm{mg} / 200 \mathrm{~g} \mathrm{BW}$, and $40 \mathrm{mg} / 200 \mathrm{~g}$ BW the Tail Flick method is equivalent to Tramadol. Ethanol leaf extract is more effective as a narcotic analgesic by the Tail Flick method.

Keywords:

Copyright () 2019 Jsscr. All rights reserved.

Inggu leaf; Analgesic; Randall Selitto; Tail Flick

$\begin{array}{ccc}\text { Received: } & \text { Accepted: } & \text { Online: } \\ \text { 2019-07-4 } & 2019-08-7 & 2019-12-9\end{array}$

\section{Pendahuluan}

Nyeri merupakan pengalaman sensoris dan emosional yang tidak menyenangkan bagi penderita, yang berkaitan dengan (ancaman) kerusakan jaringan. Nyeri disebabkan oleh rangsang mekanis, kimiawi atau fisis dapat menimbulkan kerusakan pada jaringan. Rangsangan tersebut dapat memicu pelepasan zat-zat tertentu yang disebut dengan mediator nyeri seperti histamin, bradikinin, leukotrien dan prostaglandin [1].

Analgesik atau penghalau nyeri adalah zat-zat yang dapat mengurangi atau menghilangkan rasa nyeri yang dirasakan penderitanya tanpa menghilangkan kesadaran. Obat-obat analgesik dapat dibedakan menjadi analgesik perifer (non narkotik) dan analgesik sentral (narkotik). Penggunaan obat-obat analgesik dalam jangka panjang sering sekali memberikan efek samping ringan (berupa reaksi alergi) maupun efek samping berat (gangguan sistem gastrointestinal; dispepsia, mual, muntah hingga pendarahan pada lambung). Berbagai macam efek samping yang ditimbulkan sehingga masyarakat melakukan banyak cara untuk memperoleh jaminan kesehatan yang optimal yaitu dengan memanfaatkan tanaman obat yang disebut dengan obat tradisional [2].

Salah satu tanaman yang dapat dieksplorasi sebagai bahan obat tradisional adalah daun inggu. Daun inggu secara tradisional digunakan untuk penyakit gigi, kejang pada anak, nyeri ulu hati, merangsang haid, kecekukan, sakit kepala dan bisul [3]. Dalam penelitian Pudjiastuti dan Hendarti [4] menunjukkan infusa daun inggu berefek analgetik. Daun Inggu juga berefek antiinflamasi pada dosis $100 \mathrm{mg} / \mathrm{kg}$ BB tikus [5] dan berefek antipiretik pada dosis $9 \mathrm{mg} / 200 \mathrm{~g}$ BB tikus [6].

Daun Inggu mengandung minyak atsiri [7], steroid, flavonoid, tannin, kuinon [8], dan saponin [3]. Mekanisme kerja steroid yaitu merangsang biosintesis protein lipomodulin yang dapat menghambat kerja enzimatik fosfolipase, suatu enzim yang bertanggung jawab terhadap pelepasan asam arakhidonat dan metabolitnya seperti prostaglandin, 
leukotrien, prostasiklin, tromboksan dan glukokortikoid yang dapat memblok jalur sikloogsigenase dan lipoogsigenase [1]. Selain steroid, Flavonoid bekerja dengan menghambat enzim sikloogsigenase sehingga akan mengurangi produksi asam arakhidonat sehingga mengurangi rasa nyeri, dan menghambat pengeluaran sitokin, radikal bebas, serta enzim yang berperan dalam peradangan [9].

Penelitian ilmiah perlu dilakukan sebelum dapat memanfaatkan tanaman obat agar penggunaannya dapat dipertanggung-jawabkan. Penelitian ini bertujuan untuk mengetahui efek analgesik dari ekstrak etanol daun inggu, mengetahui dosis ekstrak etanol daun inggu yang dapat memberikan aktivitas analgesik yang efektif, serta untuk mengetahui keefektifan ekstrak etanol daun inggu sebagai analgesik sentral dengan metode Tail Flick atau sebagai analgesik perifer dengan metode Paw Pressure Test (Randall Selitto).

\section{Metode}

Penelitian dilakukan di Laboratorium Fitokimia dan Laboratorium FarmakologiToksikologi, Fakultas Farmasi, Universitas Setia Budi Surakarta. Penelitian dimulai dari bulan Maret sampai selesai. Desain penelitian ini berupa penelitian eksperimental laboratorium yakni untuk menganalisa aktivitas analgetik dari ekstrak etanol Ruta angustifolia [L.] pers dengan metode Tail Flick dan Paw Pressure Test (Randall Selitto).

\subsection{Alat dan Bahan}

Alat yang digunakan dalam penelitian ini adalah blender, oven, neraca analitik, ayakan nomor 40, bejana maserasi, batang pengaduk, rotary evaporator, gelas ukur, moisture balance, beaker glass, kain flannel, timbangan tikus, corong pisah, Erlenmeyer, pipet tetes, pipet ukur, spuit injeksi, jarum sonde, sarung tangan, stopwatch, tabung reaksi, pipet tetes, lampus spiritus, seperangkat alat tail flick analgesy-meter dan UGO BASILE 37215 ITALY analgesy-meter.

Bahan yang digunakan dalam penelitian ini adalah simplisia daun inggu, etanol $96 \%$, CMC-Na, asam mefenamat, tramadol, aquadestilata atau air suling. Hewan uji yang digunakan adalah tikus putih jantan dengan berat badan 160-200 gram sebanyak 50 ekor.

\subsection{Sampel Tanaman}

Daun Inggu (Ruta angustifolia [L.] pers.) diperoleh dari petani di Tawangmangu, Karanganyar, Jawa Tengah. Daun Inggu yang digunakan adalah daun yang masih muda dan berwarna hijau muda. Sampel dideterminasi di Laboratorium Program Studi Biologi Fakultas MIPA Universitas Sebelas Maret Surakarta.

\subsection{Hewan Penelitian}

Hewan uji yang digunakan adalah tikus putih galur wistar berumur 2-3 bulan, berjenis kelamin jantan, dengan berat 150-200 gram. Jumlah hewan coba untuk masing-masing kelompok uji adalah sebanyak 5 ekor tikus, sehingga jumlah sampel hewan uji yang akan digunakan untuk satu metode analgetik adalah 25 ekor mencit. Hewan uji lalu diadaptasi selama 7 hari, ditimbang dan diberi pakan normal. Sebelum diberi perlakuan hewan uji terlebih dahulu dipuasakan selama \pm 18 jam dengan tetap diberi minum. Tikus juga diadaptasikan pada masing-masing alat selama 2-3 menit. 


\subsection{Pembuatan Ekstrak Etanol}

Daun inggu dicuci dan ditiriskan kemudian dikeringkan dengan menggunakan oven pada suhu $50^{\circ} \mathrm{C}$ selama 24 jam. Daun kering kemudian dihaluskan dengan blender menjadi serbuk lalu diayak dengan menggunakan pengayak nomor 40. Serbuk daun inggu 800 gram diekstrak dengan maserasi sederhana menggunakan etanol 96\% 6000 ml selama 5 hari. Selama proses perendaman, wadah disimpan pada suhu kamar dan terlindung dari cahaya matahari. Setelah proses perendaman selesai dilakukan penyaringan hingga didapat maserat. Ampas dari proses penyaringan diremaserasi dengan sisa pelarut yang sama sebanyak $2000 \mathrm{ml}$ hingga didapat hasil maserat yang jernih. Selanjutnya maserat yang diperoleh diuapkan dalam evaporator pada suhu $50^{\circ} \mathrm{C}$ dan selanjutnya di oven untuk mendapatkan ekstrak kental.

\subsection{Skrining Fitokimia}

\subsubsection{Uji Flavonoid}

$50 \mathrm{mg}$ serbuk dan ekstrak buah okra dimasukan dalam tabung reaksi. Selanjutnya, ditambahkan $100 \mathrm{ml}$ air panas, ditambahkan 0,1 gram serbuk magnesium, ditambahkan $2 \mathrm{ml}$ larutan Mg alkohol-HCL (1:1) dan pelarut amil alkohol dikocok kuat agar memisah. Reaksi positif ditunjukan adanya warna merah/kuning/jingga pada lapisan amil alkohol [10].

\subsubsection{Uji Steroid}

Ekstrak dilarutkan dalam 0,5 mL kloroform, ditambahkan dengan 0,5 mL asam asetat anhidrida. Selanjutnya campuran ini ditetesi dengan $2 \mathrm{~mL}$ asam sulfat pekat melalui dinding tabung tersebut. Bila terbentuk warna hijau kebiruan menunjukkan adanya steroid [10].

\subsubsection{Uji Tannin}

Identifikasi tannin. Sebanyak $1 \mathrm{mg}$ sampel dimasukkan dalam tabung reaksi dan ditambahkan 2-3 tetes $\mathrm{FeCl} 3$ 1\%. Jika larutan menghasilkan warna hijau kehitaman atau biru tua, maka sampel positif mengandung tannin [11].

\subsubsection{Uji Saponin}

Sampel dan air didihkan kemudian didinginkan lalu dikocok dan didiamkan beberapa menit. Terbentuknya busa yang stabil berarti positif terhadap saponin [12].

\subsection{Pengujian Efek Analgetik}

Pengujian aktivitas analgetika dilakukan dengan metode Paw Pressure Test (Randall Selitto) untuk menguji aktivitas analgetika perifer dan metode Tail Flick Test untuk menguji aktivitas analgetika sentral. Hewan dibagi menjadi 5 kelompok yaitu kelompok 1 sebagai kelompok kontrol yang diberi suspensi CMC Na, kelompok 2, 3 dan 4 sebagai kelompok uji I, II dan III yang diberi ekstrak etanol daun inggu dengan dosis 10, 20 dan $40 \mathrm{mg} / 200 \mathrm{~g}$ BB serta kelompok 5 sebagai kelompok pembanding yang diberi tramadol (metode Tail Flick Test) dan asam mefenamat (metode Randall Selitto Test). 


\subsubsection{Metode Tail Flick}

Metode Tail Flick Test menggunakan panas sebagai penginduksi nyeri. Prinsip metode Tail Flick Test dengan mencatat waktu yang dibutuhkan hewan uji untuk bertahan pada rangsangan termal (temperatur $50^{\circ} \mathrm{C}$ ) pada ekor, respons yang diberikan berupa penjentikan atau penarikan ekor hewan uji secara tiba-tiba [13]. Sebelum perlakuan hewan uji diuji dengan alat tail flick analgesy-meter terlebih dahulu, dicatat waktunya sebagai T0. Tikus diberikan perlakuan sesuai kelompoknya secara peroral. 30 menit kemudian tikus diuji menggunakan tail flick analgesy-meter. Kemudian dicatat waktu tikus mulai menarik atau menjentikkan ekornya. Pengujian dilakukan pada tikus ke 30, 60, 90, dan 120 menit.

\subsubsection{Metode Randall Selitto}

Metode Paw Pressure Test (Randall Selitto) menggunakan rangsangan tekanan mekanis sebagai penginduksi nyeri. Prinsip metode ini adalah telapak kaki tikus dijepit dan diberi tekanan (gram) dengan bobot tertentu yang akan terus meningkat dalam waktu singkat. Respon yang dihasilkan berupa penarikan kaki atau mengeluarkan suara secara tiba-tiba [14; 15]. Sebelum perlakuan hewan uji diuji dengan alat UGO BASILE 37215 ITALY analgesy-meter terlebih dahulu, dicatat waktunya sebagai T0. Tikus diberikan perlakuan sesuai kelompoknya secara peroral. 30 menit kemudian tikus diberi rangsangan nyeri berupa tekanan dengan alat ugo basile analgesy meter dengan tekanan beban tertentu. Pemegangan tikus harus benar dan pastikan tikus dalam keadaan tenang agar tikus bisa beradaptasi dengan alat uji. Kemudian beban dijalankan dan dihentikan jika tikus sudah memberikan respon dengan penarikan kaki. Berat beban dicatat dalam gram. Pengujian ini dilakukan selama 4 jam dengan rentang waktu tercatat, yaitu 30 menit, 60 menit, 120 menit, 180 menit dan 240 menit.

\subsection{Analisis Data}

\subsubsection{Metode Tail Flick}

Menghitung waktu respon ekor mengibas seperti menjentik, dengan rumus waktu respon setelah diberi perlakuan dikurangi waktu respon sebelum diberi perlakuan. Kemudian dihitung AUC (Area under the curve) dengan rumus:

$$
A U C_{n-1}^{n}=\frac{W t n-1+W t n}{2} \times\left(\mathrm{t}_{\mathrm{n}-1}-\mathrm{t}_{\mathrm{n}}\right)
$$

Keterangan :

Wtn-1 : Waktu respon data perekor pada tn-1

Wtn : Waktu respon data perekor pada tn

Persentase peningkatan hambat nyeri yang dihitung dengan rumus:

$$
=\frac{\mathrm{AUCp}-\mathrm{AUCk}}{A U C p} \times 100 \%
$$

Keterangan :

AUCp : AUC kurva respon rata-rata terhadap waktu kelompok perlakuan

AUCk : AUC kurva respon rata-rata terhadap waktu kelompok kontrol negatif.

Data-data yang diperoleh dianalisis dengan uji analisis varians (ANOVA) satu arah dan analisis LSD. Analisis ANOVA dinyatakan dalam rata-rata $\pm S D$, dimana hasil pengujian signifikan jika $\mathrm{p} \leq 0,05$. Analisis lanjutan LSD dilakukan dengan taraf kepercayaan $95 \%$. 


\subsubsection{Metode Randall Selitto}

Menghitung daya tahan beban penarikan kaki hewan uji dengan rumus daya tahan beban setelah diberi perlakuan (gram) dikurangi daya tahan beban sebelum diberi perlakuan (gram). Kemudian dihitung AUC (Area under the curve) dengan rumus:

$$
A U C_{n-1}^{n}=\frac{F t n-1+F t n}{2}\left(\mathrm{t}_{\mathrm{n}}-\mathrm{t}_{\mathrm{n}-1}\right)
$$

Keterangan :

Ftn-1: daya tahan beban rata-rata pada tn-1 (gram)

Ftn: daya tahan beban rata-rata pada tn (gram)

Persentase peningkatan hambat nyeri yang dihitung dengan rumus:

$$
=\frac{\text { AUCp }- \text { AUCk }}{\text { AUCp }} \times 100 \%
$$

Keterangan :

AUCk : AUC kurva daya tahan beban rata-rata terhadap waktu kontrol negatif

AUCp :AUC kurva daya tahan beban rata-rata terhadap waktu kelompok perlakuan

Data-data yang diperoleh dianalisis dengan uji analisis varians (ANOVA) satu arah dan analisis LSD. Analisis ANOVA dinyatakan dalam rata-rata $\pm S D$, dimana hasil pengujian signifikan jika $\mathrm{p} \leq 0,05$. Analisis lanjutan LSD dilakukan dengan taraf kepercayaan $95 \%$.

\section{Hasil dan Pembahasan}

Pengujian aktivitas analgetika dilakukan dengan 2 metode, yaitu metode Tail Flick Test (jentik ekor) dan metode Paw Pressure Test (Randall Selitto). Penelitian ini telah disetujui oleh Komisi Etik Penelitian Kesehatan RSUD Dr. Moewardi dengan nomor surat 707/V/HREC/2019. Determinasi daun Inggu dilakukan di Laboratorium Program Studi Biologi Fakultas MIPA Universitas Sebelas Maret Surakarta, No. 84/ UN27.9.6.4/Lab/2019 menyatakan tanaman yang digunakan sebagai bahan uji dalam penelitian adalah tanaman Inggu (Ruta angustifolia (L.) Pers.

Bagian ini adalah bagian paling penting dari artikel Anda. Analisis atau hasil penelitian harus jelas dan ringkas. Hasilnya harus meringkas (ilmiah) temuan daripada memberikan data dengan sangat rinci. Harap disorot perbedaan antara hasil atau temuan Anda dan publikasi sebelumnya oleh peneliti lain.

\subsection{Hasil Skrinning Fitokimia}

Tabel 1. Hasil uji fitokimia ekstrak daun inggu

\begin{tabular}{cc}
\hline Kandungan kimia & Hasil \\
\hline Flavonoid & Positif, terbentuk warna jingga \\
\hline Steroid & Positif, terbentuk warna hijau \\
\hline Tannin & $\begin{array}{c}\text { Positif, terbentuk warna hijau } \\
\text { kehitaman }\end{array}$ \\
\hline Saponin & Positif, terbentuk busa \\
\hline Sumber Data : Data primer yang diolah, 2019
\end{tabular}

Uji kualitatif pada ekstrak daun inggu dilakukan di Laboratorium Farmakognosi Universitas Setia Budi Surakarta dengan hasil uji identifikasi kandungan kimia menunjukan bahwa ekstrak daun inggu positif mengandung flavonoid, steroid, tannin dan saponin (dapat dilihat pada tabel 1). Sesuai dengan penelitian yang dilakukan oleh Noer dan Pratiwi (2016); Noer et al., (2018) yang melakukan uji identifikasi kualitatif 
terhadap daun inggu dengan hasil positif terhadap senyawa steroid, flavonoid, tannin dan saponin.

\subsection{Uji Analgetik Ekstrak Etanol Daun Inggu}

\subsubsection{Metode Tail Flick}

Tabel 2. Rata-rata selisih waktu respon ekor mengibas

\begin{tabular}{lllll}
\hline \multirow{2}{*}{ Kelompok } & \multicolumn{3}{c}{ Rata-rata selisih waktu respon ekor mengibas (detik) } \\
\cline { 2 - 5 } & $\Delta \mathrm{T}_{1}\left(\mathrm{~T}_{30}-\mathrm{T}_{0}\right)$ & $\Delta \mathrm{T}_{2}\left(\mathrm{~T}_{60}-\mathrm{T}_{0}\right)$ & $\Delta \mathrm{T}_{3}\left(\mathrm{~T}_{90}-\mathrm{T}_{0}\right)$ & $\Delta \mathrm{T}_{4}\left(\mathrm{~T}_{120}-\mathrm{T}_{0}\right)$ \\
\hline Kontrol negatif (CMC Na) & $1,50 \pm 0,65^{\mathrm{b}}$ & $3,87 \pm 1,36^{\mathrm{b}}$ & $4,33 \pm 2,02^{\mathrm{b}}$ & $2,95 \pm 1,67 \mathrm{~b}$ \\
\hline $\begin{array}{l}\text { Kontrol positif (Tramadol 0,9 } \\
\mathrm{mg} / 200 \mathrm{~g} \text { BB }\end{array}$ & $6,83 \pm 1,28^{\mathrm{a}}$ & $7.95 \pm 1,21^{\mathrm{a}}$ & $7,84 \pm 0,69^{\mathrm{a}}$ & $6,69 \pm 1,94^{\mathrm{a}}$ \\
\hline $\begin{array}{l}\text { Ekstrak dosis 10 mg/200 g } \\
\text { BB }\end{array}$ & $2,52 \pm 0,94^{\mathrm{b}}$ & $6,58 \pm 1,11^{\mathrm{a}}$ & $7.87 \pm 0,68^{\mathrm{a}}$ & $4,94 \pm 2,35$ \\
\hline $\begin{array}{l}\text { Ekstrak dosis 20 mg/200 g } \\
\text { BB }\end{array}$ & $3,21 \pm 1,11^{\mathrm{ab}}$ & $7,64 \pm 1,19^{\mathrm{a}}$ & $8,44 \pm 0,78^{\mathrm{a}}$ & $6,44 \pm 1,77^{\mathrm{a}}$ \\
\hline $\begin{array}{l}\text { Ekstrak dosis 40 mg/200 g } \\
\text { BB }\end{array}$ & $4,15 \pm 0,90^{\mathrm{ab}}$ & $7,93 \pm 0,89^{\mathrm{a}}$ & $8,79 \pm 0,80^{\mathrm{a}}$ & $6,27 \pm 0,79 \mathrm{a}$ \\
\hline
\end{tabular}

Sumber Data : Data primer yang diolah, 2019

Keterangan :

a $\quad=$ berbeda bermakna dengan kontrol negatif

Secara keseluruhan setiap kelompok perlakuan pada tabel 2 mengalami peningkatan ambang nyeri. Kelompok kontrol negatif memiliki selisih waktu respon hambat nyeri yang paling rendah dibandingkan kelompok kontrol positif. Menurut penelitian Wagh et al, [16], CMC Na sebagai kelompok kontrol tidak memiliki kemampuan dalam meningkatkan ambang nyeri dan kontrol lain. Kelompok kontrol positif (tramadol) pada menit ke-30 mampu menghasilkan daya tahan beban yang lebih besar dibandingkan dengan kelompok kontrol negatif. Kelompok kontrol positif yang diberikan tramadol pada menit ke-30 mampu menghasilkan peningkatan daya tahan beban yang lebih besar dibandingkan dengan kelompok kontrol negatif. Hasil uji statistik LSD menyatakan ada perbedaan signifikan antara kelompok kontrol negatif dengan kelompok kontrol positif, yang berarti kelompok kontrol positif mampu memberikan efek analgetik pada menit ke-30.

Pada menit ke-30 kelompok kontrol positif, ekstrak dosis $10 \mathrm{mg} / 200 \mathrm{~g}$ BB, 20 mg/200 g $\mathrm{BB}$, dan $40 \mathrm{mg} / 200 \mathrm{~g}$ BB memiliki rata-rata waktu respon yang tinggi dibandingkan dengan kontrol negatif setelah pemberian obat secara peroral. Kelompok kontrol positif yang diberikan tramadol mengalami peningkatan reaksi setelah pemberian sediaan uji secara peroral. Rata-rata waktu respon tikus mengibaskan ekor pada menit ke-30 yaitu 6,83 detik yang berbeda bermakna dengan kontrol negatif, pada menit ke-60 rata-rata waktu respon yaitu 7,95 detik yang berbeda bermakna dengan kontrol negatif, pada menit ke-90 rata-rata waktu respon yaitu 7,84 detik yang berbeda bermakna dengan kontrol negatif, dan pada menit ke-120 rata-rata waktu respon yaitu 6,69 detik yang berbeda bermakna dengan kontrol negatif. Hal ini menunjukkan bahwa kontrol positif (tramadol) mempunyai waktu absorbsi yang cepat dan dapat memberikan efek analgesik. Tramadol absorbsinya di usus cepat, plasma T1/2 nya 6 jam, efeknya dimulai sesudah 1 jam dan dapat bertahan 6-8 jam. Sehingga efek analgesik yang optimal muncul pada menit ke-60 dengan rata-rata waktu respon yang meningkat, hal ini sesuai 
dengan konsentrasi puncak yang dicapai setelah 1 jam pemberian kelompok perlakuan [1].

Pada kelompok perlakuan yang diberi ekstrak etanol daun inggu dengan dosis 10 $\mathrm{mg} / 200 \mathrm{~g}$ BB rata-rata waktu respon tikus mengibaskan ekor pada menit ke-30 yaitu 2,52 detik yang berbeda bermakna dengan kontrol positif dan pada menit ke-60 rata-rata waktu respon yaitu 6,58 detik yang berbeda bermakna dengan kontrol negatif yang artinya pada menit ke-60 ekstrak daun inggu mulai berefek, pada menit ke-90 rata-rata waktu respon mengalami peningkatan lagi yaitu 7,87 detik yang berbeda bermakna dengan kontrol negatif, dan pada menit ke-120 rata-rata waktu respon mengalami penurunan yaitu 4,94 detik, yang tidak terlihat kebermaknaannya. Kelompok perlakuan dosis $20 \mathrm{mg} / 200 \mathrm{~g}$ BB pada menit ke-30 dengan rata-rata waktu respon 3,21 detik yang berbeda bermakna dengan kontrol positif dan pada menit ke-60 dengan rata-rata 7,64 detik yang berbeda bermakna dengan kontrol negatif. Mengalami peningkatan pada menit ke-90 yaitu 8,44 detik, berbeda bermakna dengan kontrol negatif. Menit ke-120 mengalami penurunan yaitu 6,44 detik tidak terlihat kebermaknaannya, hal ini mungkin terjadi karena standar deviasi yang tinggi sehingga pada analisa statistik tidak terlihat kebermaknaannya. Sedangkan pada dosis $40 \mathrm{mg} / 200 \mathrm{~g}$ BB pada menit ke-30 telah terlihat efek analgesiknya dengan rata-rata waktu respon yaitu 4,15 detik. Pada menit ke-60 efek analgesiknya mengalami peningkatan dengan rata-rata waktu respon 7,93 detik, lalu mengalami peningkatan kembali pada menit ke-90 dengan rata-rata waktu respon 8,79 detik dan mengalami penurunan pada menit ke-120 dengan rata-rata waktu respon 6,27 detik.

Hasil AUC terbesar adalah kelompok positif, dan yang terendah adalah kontrol negatif. Semakin besar nilai AUC maka persentase peningkatan ambang nyeri semakin besar. Hasil AUC menunjukkan kelompok ekstrak dosis semuanya berbeda bermakna dengan kontrol negatif, dan hanya kelompok dosis $20 \mathrm{mg} / 200 \mathrm{~g}$ B yang berbeda bermakna dengan kontrol positif. Nilai AUC yang dihasilkan dapat dihitung persentase nilai peningkatan ambang nyeri sebagai daya analgesik. Persentase hambatan nyeri merupakan besarnya kemampuan senyawa uji dalam mengatasi rasa nyeri dapat dilihat pada tabel 3.

Tabel 3. Data AUC dan persentase hambat nyeri pada kelompok perlakuan

\begin{tabular}{lcc}
\hline \multicolumn{1}{c}{ Kelompok uji } & $\begin{array}{c}\text { Data AUC } \\
\text { (rata-rata } \pm S D)\end{array}$ & $\begin{array}{c}\text { Persentase peningkatan } \\
\text { ambang nyeri (\%) (rata- } \\
\text { rata } \pm \text { SD) }\end{array}$ \\
\hline Kontrol negatif (CMC Na) & $537,39 \pm 226,39^{\mathrm{b}}$ & - \\
\hline $\begin{array}{l}\text { Kontrol positif (Tramadol 0,9 mg/200 g } \\
\text { BB) }\end{array}$ & $1203,99 \pm 161,71^{\mathrm{a}}$ & $54,60 \pm 18,37$ \\
\hline Ekstrak dosis 10 mg/ 200 g BB & $962,16 \pm 136,48^{\mathrm{ab}}$ & $41,20 \pm 29,02$ \\
\hline Ekstrak dosis $20 \mathrm{mg} / 200 \mathrm{~g} \mathrm{BB}$ & $1097,64 \pm 172,71^{\mathrm{a}}$ & $52,20 \pm 18,53$ \\
\hline Ekstrak dosis 40 mg/ 200 g BB & $1179,06 \pm 74,31^{\mathrm{a}}$ & $54,00 \pm 20,14$ \\
\hline $\begin{array}{l}\text { Sumber Data : Data primer yang diolah, 2019 } \\
\text { Keterangan : } \\
\text { a = Berbeda bermakna dengan kontrol negatif } \\
\text { b = Berbeda bermakna dengan kontrol positif }\end{array}$ & \\
\hline
\end{tabular}


Daya aktivitas analgesik pada sediaan uji ditunjukkan dengan persentase hambat nyeri yang lebih besar atau sama dengan 50\% dibandingkan kelompok kontrol negatif, maka dianggap efektif sebagai analgesik [17]. Berdasarkan tabel diatas persentase ambang nyeri yang dihasilkan oleh ekstrak dosis terendah $10 \mathrm{mg} / 200 \mathrm{~g}$ BB adalah 41,20\%, hal ini menunjukkan bahwa pada dosis $10 \mathrm{mg} / 200 \mathrm{~g}$ BB memiliki aktivitas analgesik yang lemah karena. Berdasarkan data statistik ekstrak etanol daun inggu dosis $20 \mathrm{mg} / 200 \mathrm{~g}$ BB dan $40 \mathrm{mg} / 200 \mathrm{~g}$ BB memiliki aktivitas analgesik yang sebanding dengan kontrol positif.

Pemberian ekstrak etanol daun inggu terbukti mampu meningkatkan rata-rata reaksi sebagai respon peningkatan ambang nyeri. Secara statistik dengan uji Shapiro-Wilk persentase peningkatan ambang nyeri terdistribusi normal $(p<0,05)$ dan uji levene diperoleh nilai signifikasi $0,431(p>0,05)$ artinya varian data homogen. Selanjutnya dilakukan uji one way ANOVA dimana hasil menunjukkan $\mathrm{P}=0,748(\mathrm{p}>0,05)$ berarti tidak terdapat perbedaan bermakna antara kelompok perlakuan. Hal ini berarti tramadol dan variasi dosis ekstrak etanol daun inggu memilik efek analgesic pada tikus putih jantan. Walaupun ektrak etanol daun inggu dosis $10 \mathrm{mg} / 200 \mathrm{~g}$ BB memiliki hasil terendah tetapi saat diuji statistic tidak ada perbedaan atau sebanding atau sama antar kelompok perlakuan.

Ekstrak etanol daun inggu mengandung senyawa metabolit sekunder seperti flavonoid, tannin, dan saponin. Wemay et al. [18] menyatakan bahwa senyawa terpenoid dan flavonoid mampu menghambat lintasan enzim siklooksigenase. Saponin terdiri dari membran steroid yang mampu berinteraksi dengan membran lipid seperti fosfolipid yang merupakan precursor prostaglandin [19]. Saponin juga mempunyai efek analgesik dengan cara menghambat sintesis PGE2 [20].

\subsubsection{Metode Paw Pressure Test Randall Selitto}

Hasil yang didapat dalam pengamatan berupa nilai berat beban tertentu yang selanjutnya digunakan dalam perhitungan AUC untuk menentukan nilai persentase ambang nyeri. Hasil rata-rata peningkatan ambang nyeri oleh suatu beban pada kelompok perlakuan tiap waktu dilihat pada tabel 4.

Tabel 4. Rata-rata selisih daya tahan beban metode Randall Selitto

\begin{tabular}{|c|c|c|c|c|c|}
\hline \multirow[t]{2}{*}{ Kelompok } & \multicolumn{5}{|c|}{ Rata-rata selisih daya tahan beban (gram) } \\
\hline & T30 & T60 & T120 & T180 & $\mathrm{T} 240$ \\
\hline Kontrol negatif (CMC Na) & $18,00 \pm 4,42^{\mathrm{b}}$ & $30,00 \pm 4,30^{\mathrm{b}}$ & $42,20 \pm 4,38^{\mathrm{b}}$ & $39,60 \pm 7,92^{b}$ & $26,60 \pm 8.11^{b}$ \\
\hline $\begin{array}{l}\text { Kontrol positif (Asam } \\
\text { mefenamat } 9 \mathrm{mg} / 200 \mathrm{~g} \\
\mathrm{BB} \text { ) }\end{array}$ & $59,20 \pm 22,51^{\text {a }}$ & $113,40 \pm 22,32^{a}$ & $128,00 \pm 16,79 a$ & $76,80 \pm 26,36^{a}$ & $56,80 \pm 26,7 a$ \\
\hline $\begin{array}{l}\text { Ekstrak dosis } 10 \mathrm{mg} / 200 \mathrm{~g} \\
\text { BB }\end{array}$ & $20,60 \pm 5,59 \mathrm{~b}$ & $70,00 \pm 18,29 \mathrm{ab}$ & $89,00 \pm 23,02^{a b}$ & $61,20 \pm 16,96 \mathrm{ab}$ & $40,80 \pm 14,96$ \\
\hline $\begin{array}{l}\text { Ekstrak dosis } 20 \mathrm{mg} / 200 \mathrm{~g} \\
\text { BB }\end{array}$ & $20,40 \pm 11,42^{b}$ & $75,40 \pm 28,29 \mathrm{ab}$ & $104,40 \pm 36,38^{a}$ & $75,40 \pm 10,74$ a & $65,40 \pm 8,53^{a}$ \\
\hline $\begin{array}{l}\text { Ekstrak dosis } 40 \mathrm{mg} / 200 \mathrm{~g} \\
\text { BB }\end{array}$ & $13,00 \pm 7,04^{\mathrm{b}}$ & $75,80 \pm 10,18^{a b}$ & $109,80 \pm 17,84^{\mathrm{a}}$ & $89,00 \pm 12,90$ a & $71,80 \pm 21,19 a$ \\
\hline \multicolumn{6}{|c|}{ Sumber Data: Data primer yang diolah, 2019} \\
\hline \multicolumn{6}{|l|}{ Keterangan : } \\
\hline \multicolumn{6}{|c|}{$\mathrm{a}=$ berbeda bermakna dengan kontrol negatif } \\
\hline
\end{tabular}


Berdasarkan tabel 4 kelompok kontrol negatif (CMC Na), kelompok kontrol positif (Asam mefenamat), dan kelompok perlakuan ekstrak etanol daun inggu pada menit ke30 mengalami peningkatan reaksi tikus menahan rangsangan nyeri. Kelompok kontrol negatif (CMC Na) menghasilkan rata-rata nilai daya tahan beban yang paling rendah dibandingkan dengan kelompok kontrol lain. Hal ini terjadi karena CMC Na tidak memiliki kemampuan menangani nyeri karena tidak mengandung zat aktif [16].

Kelompok kontrol positif (asam mefenamat) pada menit ke-30 secara statistik non parametric menunjukkan perbedaan yang signifikan dengan kontrol negatif yang berarti sudah terjadi penghambatan nyeri oleh asam mefenamat pada menit ke-30. Untuk menit ke-60 rata-rata daya tahan beban yang dihasilkan oleh pemberian asam mefenamat meningkat, efek analgetik kelpmpok asam mefenamat mencapai puncak pada menit ke-120 dan menurun pada menit ke 180, dan menit ke-240. Hasil pengujian ini sesuai dengan penelitian yang dilakukan oleh Oktavianus et al. [21] bahwa efek analgesik pada asam mefenamat mencapai puncak pada menit ke-120 karena konsentrasi puncak dicapai 2-4 jam setelah pemberian oral. Faktor perbedaan spesies antara manusia dengan hewan uji bisa saja menyebabkan perbedaan pada proses metabolisme, namun efek analgesik asam mefenamat dalam metode ini sesuai dengan teori yang dinyatakan oleh Gunawan et.al [22] bahwa efek analgesik asam mefenamat mencapai puncak dalam waktu 2-4 jam.

Menit ke-60 rata-rata respon daya tahan beban pada semua kelompok perlakuan ekstrak etanol daun inggu meningkat dan berbeda bermakna dengan kontrol negatif, berarti kelompok perlakuan ekstrak etanol daun inggu mulai memberikan efek analgetik pada menit ke-60. Kelompok perlakuan yang diberi sediaan uji ekstrak etanol daun inggu dengan dosis $10 \mathrm{mg} / 200 \mathrm{~g}$ BB pada menit ke-60 memberikan rata-rata respon daya tahan beban 70 gram, menit ke-120 mengalami peningkatan rata-rata respon daya tahan beban 89 gram, mulai mengalami penurunan pada menit ke-180 dan ke-240. Dosis $20 \mathrm{mg} / 200$ g BB mulai memberikan efek analgesik pada menit ke-60 dengan rata-rata respon daya tahan beban 75,40 gram, dan pada menit ke- 60 mengalami peningkatan rata-rata respon daya tahan beban 104,40 gram. Pada dosis 40 mg/200 g BB mulai memberikan efek analgesik pada menit ke-60 dengan rata-rata respon daya tahan beban 75,80 gram dan mengalami peningkatan daya tahan beban pada menit ke-120 dengan rata-rata respon daya tahan beban 109,80 gram. Peningkatan ambang nyeri yang terjadi menyatakan adanya daya hambat nyeri sehingga tikus mampu menahan beban yang berat ketika beban dijalankan.

Keseluruhan data respon peningkatan ambang nyeri yang berupa peningkatan daya tahan beban selanjutnya digunakan untuk menghitung AUC dan persentase peningkatan ambang nyeri sebagai daya analgesik (tabel 5).

Semakin besar nilai AUC maka persentase peningkatan ambang nyeri semakin besar. Hasil AUC menunjukkan kelompok ekstrak dosis semuanya berbeda bermakna dengan kontrol negatif, dan kelompok dosis $10 \mathrm{mg}$ dan $20 \mathrm{mg} / 200 \mathrm{~g}$ BB berbeda bermakna dengan kontrol positif. AUC yang dihasilkan dapat dihitung persentase nilai peningkatan ambang nyeri sebagai daya analgesik. Persentase hambatan nyeri merupakan besarnya kemampuan senyawa uji dalam mengatasi rasa nyeri dapat dilihat pada tabel 5. 
Tabel 5. Data AUC dan persentase peningkatan ambang nyeri pada kelompok perlakuan

\begin{tabular}{|c|c|c|}
\hline Kelompok uji & $\begin{array}{c}\text { Data AUC } \\
\text { (rata-rata } \pm \text { SD) }\end{array}$ & $\begin{array}{l}\text { Persentase peningkatan } \\
\text { ambang nyeri }(\%) \text { (rata- } \\
\text { rata } \pm \text { SD) }\end{array}$ \\
\hline Kontrol negatif (CMC Na) & $7596 \pm 907,01^{b}$ & - \\
\hline $\begin{array}{l}\text { Kontrol positif (Asam } \\
\text { mefenamat } 9 \mathrm{mg} / 200 \mathrm{~g} \mathrm{BB})\end{array}$ & $20871 \pm 4038,68^{a}$ & $62,60 \pm 5,94$ \\
\hline Ekstrak dosis $10 \mathrm{mg} / 200 \mathrm{~g}$ BB & $14004 \pm 3528,29 \mathrm{ab}$ & $42,60 \pm 16,80^{*}$ \\
\hline Ekstrak dosis $20 \mathrm{mg} / 200 \mathrm{~g}$ BB & & $54,20 \pm 8,87$ \\
\hline Ekstrak dosis $40 \mathrm{mg} / 200 \mathrm{~g}$ BB & $\begin{array}{l}16755 \pm 2348,23^{\mathrm{ab}} \\
17,883 \pm 1770,43^{\mathrm{a}}\end{array}$ & $57,40 \pm 4,83$ \\
\hline
\end{tabular}

Daya aktivitas analgesik pada sediaan uji ditunjukkan dengan persentase hambat nyeri lebih besar atau sama dengan $50 \%$ dari kelompok kontrol negatif, maka dianggap efektif sebagai analgesik [17]. Persentase ambang nyeri yang dihasilkan oleh ekstrak dosis terendah $10 \mathrm{mg} / 200 \mathrm{~g} \mathrm{BB}$ adalah 42,60\%, hal ini menunjukkan bahwa pada dosis 10 $\mathrm{mg} / 200 \mathrm{~g}$ BB memiliki aktivitas analgesik yang lemah. Berdasarkan data statistik ekstrak etanol daun Inggu dosis $20 \mathrm{mg} / 200 \mathrm{~g}$ BB dan dosis $40 \mathrm{mg} / 200 \mathrm{~g}$ BB memiliki aktivitas analgesik yang sebanding dengan kontrol positif. Persentase hambat nyeri terbesar terlihat pada ekstrak dosis $40 \mathrm{mg} / 200 \mathrm{~g}$ BB yaitu $57,40 \%$ dan dosis $20 \mathrm{mg} / 200$ $\mathrm{g}$ BB yaitu 54,20\%, hal ini dapat disimpulkan bahwa pada esktrak dosis $40 \mathrm{mg} / 200 \mathrm{~g}$ BB dan $20 \mathrm{mg} / 200 \mathrm{~g}$ BB memiliki lebih banyak kandungan senyawa aktif dengan jumlah yang terabsorbsi lebih banyak sehingga dapat menimbulkan efek analgesik yang lebih baik.

Pemberian ekstrak etanol daun inggu terbukti mampu meningkatkan daya tahan beban sebagai respon peningkatan ambang nyeri. Hasil secara statistik dengan uji ShapiroWilk persentase peningkatan ambang nyeri semua kelompok terdistribusi normal $(\mathrm{p}>0,05)$ dan uji levene yang diperoleh nilai signifikasinya $0,013(\mathrm{p}<0,05)$ artinya varian data tidak homogen. Selanjutnya dilakukan uji non parametric Kruskal-Wallis, menunjukkan bahwa nilai $\mathrm{p}=0,087(\mathrm{p}>0,05)$ berarti tidak ada perbedaan bermakna antara kelompok kontrol positif dengan kelompok dosis $10 \mathrm{mg} / 200 \mathrm{~g}$ BB, $20 \mathrm{mg} / 200 \mathrm{~g}$ $\mathrm{BB}$, dan $40 \mathrm{mg} / 200 \mathrm{~g}$ BB. Hal tersebut berarti bahwa asam mefenamat dan variasi dosis ekstrak etanol daun inggu memiliki efek analgesik pada tikus putih jantan. Walaupun ektrak etanol daun inggu dosis $10 \mathrm{mg} / 200 \mathrm{~g}$ BB memiliki hasil terendah tetapi saat diuji statistik tidak ada perbedaan atau sebanding atau sama antar kelompok perlakuan. Persentase peningkatan ambang nyeri merupakan besarnya kemampuan senyawa uji dalam mengatasi nyeri akibat beban yang dijalankan. Semakin besar dosis semakin besar juga daya beban yang mampu ditahan oleh hewan uji.

Hasil uji analgetik dengan metode Tail flick dan metode Randall Selitto menunjukkan hasil yang sama dimana dosis $20 \mathrm{mg} / 200 \mathrm{~g}$ BB dan dosis $40 \mathrm{mg} / 200 \mathrm{~g}$ BB memiliki efek analgetik yang sebanding dengan kontrol positifnya. 


\section{Kesimpulan}

Dapat disimpulkan bahwa ekstrak etanol daun inggu mempunyai aktivitas analgesik dengan metode Tail Flick maupun Randall Selitto, pada dosis 40 mg/200 g BB ekstrak etanol daun inggu mempunyai aktivitas analgesik tertinggi dan sebanding dengan kontrol positif. Ekstrak etanol daun inggu lebih efektif sebagai analgesik narkotik dengan metode Tail Flick yaitu pada dosis $10 \mathrm{mg} / 200 \mathrm{~g} \mathrm{BB}, 20 \mathrm{mg} / 200 \mathrm{~g}$ BB, dan 40 $\mathrm{mg} / 200 \mathrm{~g}$ BB karena sebanding dengan pembanding.

\section{Ucapan Terima Kasih}

Penulis mengucapkan terima kasih kepada Universitas Setia Budi Surakarta melalui Lembaga Penelitian dan Pengabdian Masyarakat (LPPM) Universitas Setia Budi Surakarta yang telah membiayai penelitian ini, sehingga penelitian ini dapat terlaksana dengan baik.

\section{Referensi}

[1] Tjay TH, Rahardja K. 2007. Obat-obat penting: Khasiat, Penggunaan, dan Efekefek sampingnya, edisi ke-6.Cetakan pertama, Gramedia, Jakarta.

[2] Katno, Pramono S. 2002. Tingkat manfaat dan keamanan Tanaman Obat dan Obat Tradisional. Yogyakarta: Fakultas Farmasi UGM.

[3] Noer S., Pratiwi RD., Gresinta E., 2018, Penetapan Kadar Senyawa Fitokimia (Tanin, Saponin Dan Flavonoid Sebagai Kuersetin) Pada Ekstrak Daun Inggu (Ruta angustifolia L.), Jurnal Ilmu-ilmu MIPA, e. ISSN: 2503-2364

[4] Pudjiastuti, Hendarti N., 1999. Penelusuran Beberapa Tanaman Obat Berkhasiat Sebagai Analgetik, Media Litbang Kesehatan Volume IX No 3.

[5] Kusniawati, M.A., 2018, Aktivitas Antiinflamasi Ekstrak Etanol Daun Inggu (Ruta angustifolia [1] pers) Pada Tikus Putih Jantan Dengan Metode Induksi Karagenan Dan Radiasi Uv (Skripsi), Fakultas Farmasi Universitas Setiabudi, Surakarta.

[6] Pratiwi, N.M., 2018, Aktivitas Antipiretik Ekstrak Etanol Daun Inggu (Ruta angustifolia (1.) pers.) Pada Tikus Putih Jantan Yang Diinduksi Demam Dengan Vaksin Dtp-Hb-Hib. (Skripsi). Fakultas Farmasi. Universitas Setia Budi. Surakarta.

[7] Saputri, Wina Adestia, 2013, Efek Antikonvulsi Ekstrak Etanol Daun Inggu (Ruta angustifolia PERS.) Pada Mencit Galur BALB/C Dengan Induksi PTZ Secara In Vivo (Skrpsi), Universitas Muhammadiyah Purwokerto.

[8] Noer S., Pratiwi RD., 2016. Uji Kualitatif Fitokimia Daun Ruta Angustifolia, Jurnal Ilmu-ilmu MIPA, Faktor Exacta 9(3): 200-206, 2016 p-ISSN: 1979-276X. e- ISSN: 2502-339X.

[9] Patel JM. 2008. A review of potential health benefits of flavonoids. Lethbridge Undergraduate Reserch Journal. ISSN 1718-8482.

[10] Baud, G.S., Sangi, M.S., Koleangan, H.S.J., 2014, Analisis Senyawa Metabolit Sekunder Dan Uji Toksisitas Ekstrak Etanol Batang Tanaman Patah Tulang (Euphorbia tirucalli L.) Dengan Metode Brine Shrimp Lethality Test (BSLT), Jurnal Ilmiah Sains, 14(2): 108.

[11] Wijayah, Alfonsius Bryan., Gayatri Citraningtyas., Frenly Wehantouw. 2014. Potensi Ekstrak Etanol Tangkai Daun Talas (Colocasia esculenta L) Sebagai Alternatif Obat Luka Pada Kulit Kelinci (Oryctolagus cuniculus). Skripsi. Program Studi Farmasi FMIPA UNSRAT Manado. 
[12] Mustikasari K, Ariyani D. 2008. Studi Potensi Binjai (Mangifera caesia) dan Kasturi (Mangifera casturi) Sebagai Antidiabetes melalui Skrining Fitokimia pada Akar dan Batang. Sains dan Terapan Kimis 2; 64-73.

[13] Yusuf H. 2001. Efek analgesia ekstrak daun klausena (Clausena anisa Hook.f.) pada tikus putih dengan metode rat tail analgesy test [Tesis]. Medan: Universitas Sumatera Utara.

[14] Wong, C.E., 2009, Uji Analgesik Kombinasi Tapak Liman dan Patikan Kebo Dengan Metode Paw Pressure Test pada Tikus Putih, (Skripsi), Universitas Surabaya, Surabaya.

[15] Kayser V. 2013 Randall-Selitto Paw Pressure Test. In: Gebhart G.F., Schmidt R.F. (eds) Encyclopedia of Pain. Springer, Berlin, Heidelberg. https://link.springer.com/referenceworkentry/10.1007\%2F978-3-642-287534_3726 (21 Agustus 2019).

[16] Wagh N.K., Hemantkumar S., Deokar., Badal S., Rathi., Subhash L., Bodhankar, Vithal M.K. 2006. Anti-inflammatory and Analgesic Activity of 4'Methylbiphenyl-2-(Substituted Phenyl)Carboxamide Analog in Animal Models of Inflammation. Pharmacologyonline. Vol: 2.

[17] Puspitasari, H., Listyawati, S., Widiyani, T., 2003. Aktivitas Analgetik Ekstrak Umbi Teki (Cyperus rotundus L.) pada Mencit Putih (Mus musculus L.) Jantan. Biofarmasi, ISSN: 1693-2242. 1(2).

[18] Wemay M.A, Fatimawali, Wehantaouw F. 2013. Uji fitokimia dan aktivitas analgesik ekstrak etanol tanaman kucing-kucingan (Acalypha indica L) pada tikus putih betina galus wistar (Rattus novergicus L). Jurnal Ilmiah Farmasi. 2(3):1-8.

[19] Hidayati R.S, Napitupulu R.M. 2015. Kitab Tumbuhan Obat. Cetakan I. Jakarta: Agriflo.

[20] Adesokan AA, et.al., 2008. Effect of administration aqueous and ethanol extracts of Enantia chlorantha stem bark on brewer's yeast induced pyresis in rats. African J of Biochemustry. 2:165-169

[21] Oktavianus S, Fatmawati, Widya AL. 2014. Uji Efek analgetik ekstrak etanol daun papaya (Carica Papaya L) pada mencit putih jantan (Mus mucculus). Jurnal Ilmiah Farmasi 3: 2.

[22] Gunawan SG, Setiabudy Riyanto, Nafrialdi, Elysabeth. 2007. Farmakologi dan Terapi edisi 5. Departemen Farmakologi dan Fakultas Kedokteran Universitas Indonesia. 